\title{
Experiences of patients who had undergone coronary artery bypass graft surgery with strengths-based nursing care
}

\author{
Yasemin ALTINBAS ${ }^{1}$ (D), Meryem YAVUZ van GIERSBERGEN² (D) \\ ${ }^{1}$ Department of Surgical Nursing, School of Health Sciences, Adiyaman University, Adiyaman, Turkey. \\ ${ }^{2}$ Department of Surgical Nursing, School of Nursing, Ege University, Izmir, Turkey.
}

\author{
Corresponding Author: Yasemin ALTINBAS
}

E-mail: yaseminaltinbas_27@hotmail.com

Submitted: 13.08.2020 Accepted: 29.11.2020

\begin{abstract}
Objective: Strengths-based nursing is a new approach and care philosophy and it is still unclear how it affects patients in the surgery period. The aim of this study was to determine the experiences of patients who had undergone coronary artery bypass graft surgery managed with this philosophy.

Patients and Methods: This qualitative study consisted of 23 patients who had undergone coronary artery bypass graft surgery in the Cardiovascular Surgery Department of a university hospital in Izmir, Turkey. The data were collected using Individual Identification Form, Semi-structured Interview Forms, SWOT Analysis Form and Classification of Qualitative Strengths Form. Thematic data analysis was used to evaluate patient answers to the research questions.

Results: According to the analyses performed, seven main themes consisting of "Perception of Being Strong", "Perception of Being Weak", "Care Process", "Effects of Heart Disease", "Reason for the Occurrence of the Disease", "Need for Knowledge" and "Solution Seeking" were determined in the preoperative interviews, and five main themes consisting of "Perception of Being Strong", "Perception of Being Weak", "Surgery", "Care Process" and "Education" were determined in the postoperative interviews.

Conclusion: This new philosophy in patient management has positive effects because it increases patients' hopes for life, healing and facilitating adaptation to the surgical procedure.

Keywords: Coronary artery bypass graft surgery, Patient, Experience, Strengths-based nursing care.
\end{abstract}

\section{INTRODUCTION}

Many people die for various reasons including cardiovascular diseases (CVDs) in the world every passing year, and CVDs rank first among the causes of death around the world. According to data of the World Health Organization (WHO), 17.9 million people died from CVDs in 2016, and CVDs constituted 31\% of all global deaths [1]. Coronary artery disease (CAD) is the most common among CVDs nowadays, coronary artery bypass graft surgery (CABGS) is the most commonly used method to reduce mortality and symptoms and to prolong life in the surgical treatment of CAD [2]. While surgical intervention performed by this method has therapeutic and positive effects on patients, it can also be observed to cause physiological, psychological and social changes. Physiological, behavioral, environmental and

* This study was presented at the 6th World Nursing and Healthcare Conference, London, UK between 22-24th July, 2016. Yasemin Altinbas was nominated 'Young Researcher' for her presentation by the scientific committee of the conference. socioeconomic factors play a role in the effective management and nursing care of chronic diseases. The patients found ways to cope with the process by changing their environment, motivating themselves and reducing their demands. They found that the psychological effects of the disease could be coped by self-control, with the support of family, friends and spouse [35]. For these reasons, patients may need support to manage their symptoms and improve the prognosis in the surgical process.

In recent years, in these patients who underwent CABGS, the main goals of health care were to provide early mobilization, to reduce possible complication rates, to overcome deficiencies, to improve compliance to treatment and the quality of life and to ensure early discharge. It is necessary to ensure the participation of patients in their care and to encourage them to take part in their care in order to achieve these goals [6]. For quality patient management, to provide holistic care to individuals in the surgical process, to allow individuals to take a decision, and to

How to cite this article: Altinbas Y, Yavuz van Giersbergen M. Experiences of patients who had undergone coronary artery bypass graft surgery with strengths-based nursing care. Marmara Med J 2021;34(1):57-65. doi: 10.5472/marumj.869065 
teach them to use their resource mobilization skills (focusing on individuals' strengths) are among the roles and responsibilities of the nurse [6,7]. Strengths-Based Nursing Care (SBNC), published by Gottlieb in 2014, was a new philosophy of thinking in nursing and based on positive, the best and best working areas [8]. According to this philosophy, nurses and health professionals are charged with the responsibility of helping individuals find their own strengths to deal with both everyday challenges and adversities that threaten their integrity, that is, their sense of wholeness as well as the intactness of their lives [9].

This study will be a guide for health teams with respect to improving the quality of life of individuals, ensuring their participation in their own care and their compliance to treatment, and preventing possible complications. Besides, this study is considered a contribution to the literature as no study using this philosophy in patients undergoing heart surgery has been observed so far.The aim of this study was to determine experiences of patients undergoing coronary artery bypass graft surgery with SBNC.

\section{MATERIALS and METHODS}

A qualitative design was used with the purpose of explaining and describing facts of a phenomenon or an experience [10] using the participants' own language and staying close to the data [11]. The researcher is interested in the personal experiences of the participant and examines the perceptions of the individual and the meanings attributed to the events using in-depth interviews with patients.

\section{Study Population}

This qualitative study consisted of 23 patients undergoing coronary artery bypass graft surgery in the Cardiovascular Surgery Department of a university hospital in Izmir, Turkey. Purposive sampling method was used in participant selection. Twenty-three patients who agreed to participate in the study, over18 years old, undergoing $\mathrm{CABG}$ for the first time, were hospitalized at least two days before surgery and were physically and psychologically qualified to have an interview were included. Patients who met the inclusion criteria were invited to the study by face to face method on the first day of hospitalization. The researcher gave detailed information about herself and the study and consent was obtained from the patients to participate in the current study. In total, 32 patients were invited to the study, a total of 9 patients were excluded, including 5 patients who refused to participate in the study and 4 patients who retracted from surgery. Twenty-three patients agreed to participate.

Research ethics board approval for this research was obtained from the Scientific Ethic Committee of a university (Ethics Committee approval no. 2015-86) and written permission was taken from the Administration of the University Hospital where the study was to be conducted. Written and verbal permissions of the patients who agreed to participate in the study were obtained. Patients were told that they could withdraw at any stage of the research and the 'Principle of Respect for Autonomy' was fulfilled. It was stated that the information obtained in the research would be kept confidential and the 'Principle of Confidentiality and Protection of Confidentiality' was fulfilled. Ethical principles were fulfilled based on the 'Principle of Beneficence and Nonmaleficence?.

\section{Data Collection Tools}

Before the interview questions were prepared, international literature was reviewed and the relevant qualitative and quantitative studies were used $[2,6,12,13]$. Before starting to collect data, a total of 5 experts consisting of Faculty Members of Anthropology, Sociology, Curriculum and Instruction and Surgical Nursing were consulted for their opinions about the questions, and the questions were rearranged and finalized in line with the suggestions.

The data were collected in both processes before and after surgery, when the patient was interactive and communicative in the surgical process; since it is a whole that includes preoperative, intraoperative and postoperative management. The data were collected using the individual identification form (Socio-demographic Characteristics), semi-structured interview forms, Strengths, Weaknesses, Opportunities and Threats (SWOT) analysis form and the form of classification of qualitative strengths (Knowledge and Wisdom, Courage, Humanity, Justice, Moderation and Superiority).

The preoperative semi-structured interview form included the following questions:

-How has your illness affected you from physiological, psychological and social aspects?

-How did you decide to have surgery?

-What are your strengths, and the factors that make you weak?

-How do you think your strengths will affect your care process?

The postoperative semi-structured interview form included the following questions:

-What do you feel about your surgery?

-Were you able to use your strengths in accordance with the care provided to you during surgery?

-How did you use them?

-How did bringing your strengths into the forefront affect your recovery?

-What are your future expectations for using your strengths?

\section{Data Collection Method}

The data were collected by conducting in-depth interviews on the day the patients were admitted to the clinic and the day they were discharged, and using individual trainings which are valid and reliable learning tools received from 10 experts consisting of 5 Faculty Members of Surgical Nursing and 5 Cardiovascular Surgery Nurses. The interviews with patients were conducted with preoperative and postoperative semi-structured interview forms by the first researcher. She was trained in qualitative methods and attended formal training courses including 
Qualitative Research Methods, Qualitative Data Analysis: Analysing Qualitative Interviews, Body Language, Effective Communication and Diction. She had worked as a nurse in the cardiovascular surgery service. In-depth interviews were conducted alone with the patient in the patient room or in the meeting rooms (depending on the request of the patient) in the clinic (Figure 1).
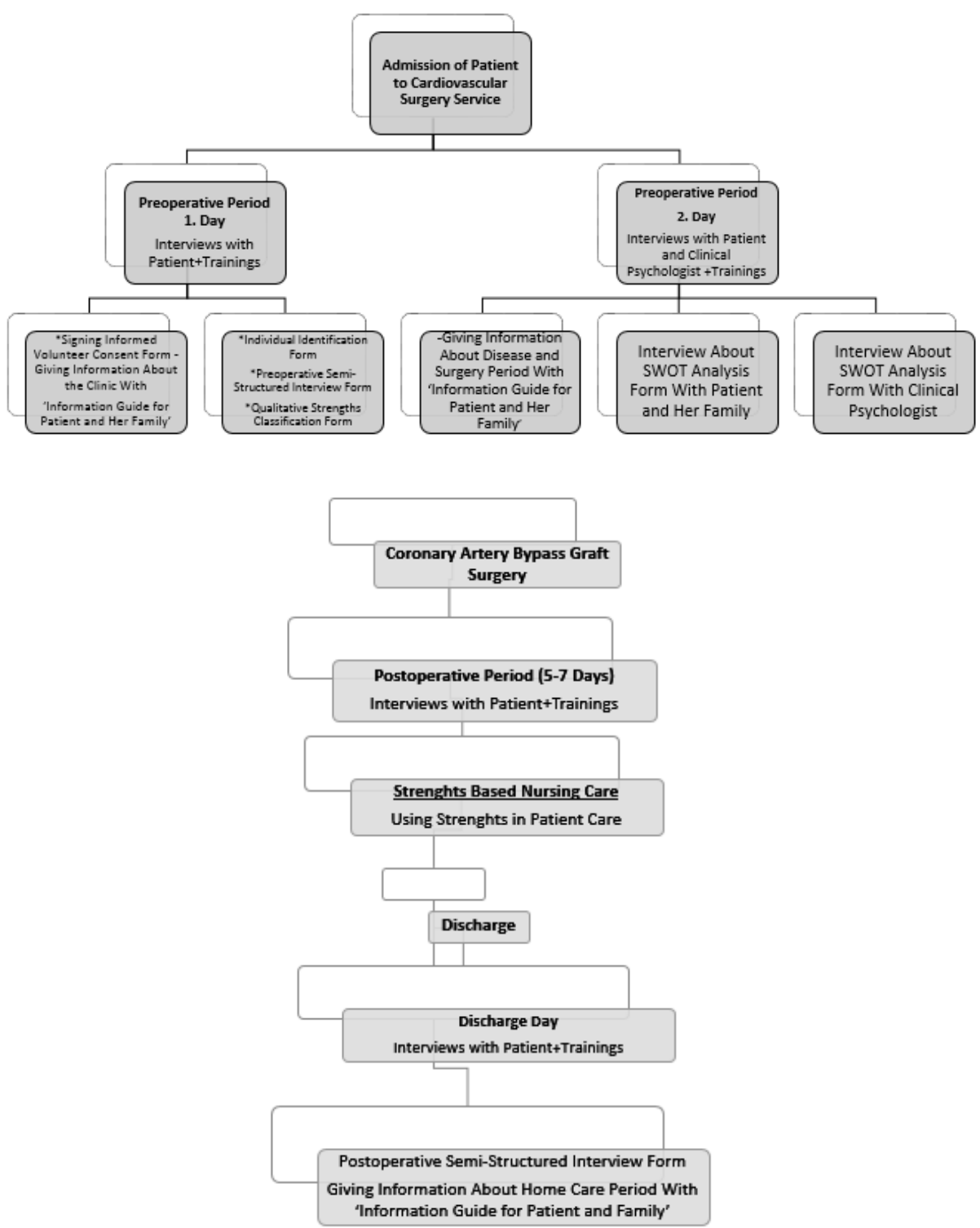

Figure 1. Data collection chart

Data collection was maintained up to the stage at which the concepts and processes that could be the answer to the research questions began to repeat (saturation point). As the study progressed, data saturation was assessed by the research group by evaluating the richness of the data being collected, whether new substantive codes were being elicited, and whether new thematic categories were emerging. When saturation was considered to have been reached, a further three interviews were undertaken to confirm no new substantive codes were elicited. The interviews were audio recorded, transcribed verbatim, and validated by relistening to the recording by the researcher. The mean length of the interview was 53 minutes (min.45-max.72) on the day the participants were admitted to the clinic in the preoperative period, and 38 minutes (min.32-max.50) on the postoperative discharge day. The data collection was performed between August-November 2015 in the Cardiovascular Surgery Department of a university hospital. 


\section{Data Analysis}

Thematic data analysis was used to evaluate answers to the research questions [14]. The data management was assured using the NVivo 12. All interviews were transcribed verbatim word by word. Transcribed data were read and reread, and commonalities between the transcripts were noted and led to the development of themes [14]. Themes were analyzed for connections across emergent themes and were validated through comparison with the original data sources until data saturation occurred. Participant narratives and words served to inform the naming of themes [14]. Expert opinion was obtained from the clinical psychiatrist to determine the strengths of the patients and the factors that make them weak, transcripts were returned to participants and individual trainings were provided in accordance with the needs that emerged through the interviews. Quotations were translated to English, and throughout the analysis process, the patterns were discussed with all authors until consensus was reached. Examples of quotations are illustrated in the text and numbered from 1 to 23, representing all participants.

\section{RESULTS}

The average age of the patients participating in the study was $60.91 \pm 9.67$ years. Of the patients, $73.9 \%$ were male, $95.7 \%$ were married, $56.5 \%$ were primary school graduates and retired, $95.7 \%$ had social security, $56.5 \%$ had previously undergone surgery and $87.0 \%$ were on continuous medication. The mean hospitalization day of the patients participating in the study was $12.73 \pm 2.75$ days

The results consisted of two parts. The first part included qualitative data including experiences for the preoperative period (Figure 2), and the second part for the postoperative period (Figure 3).

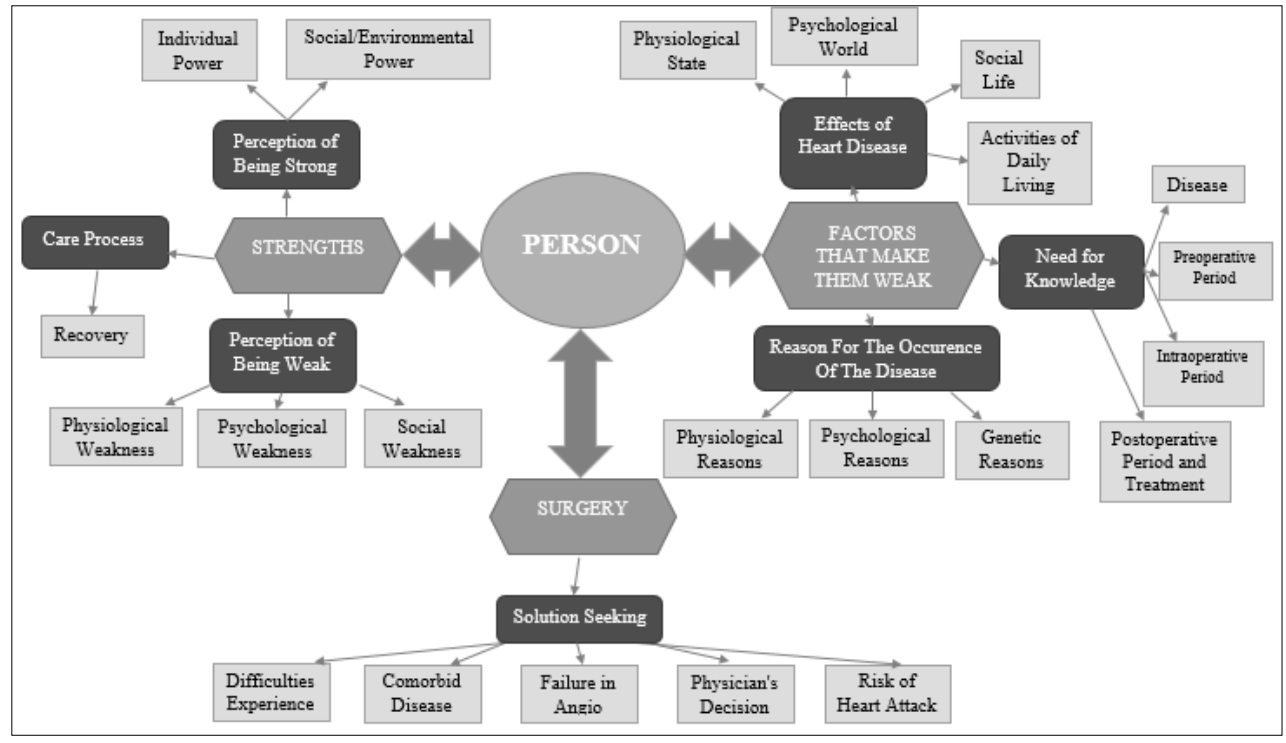

Figure 2. Categories, main themes and sub-themes of the preoperative period

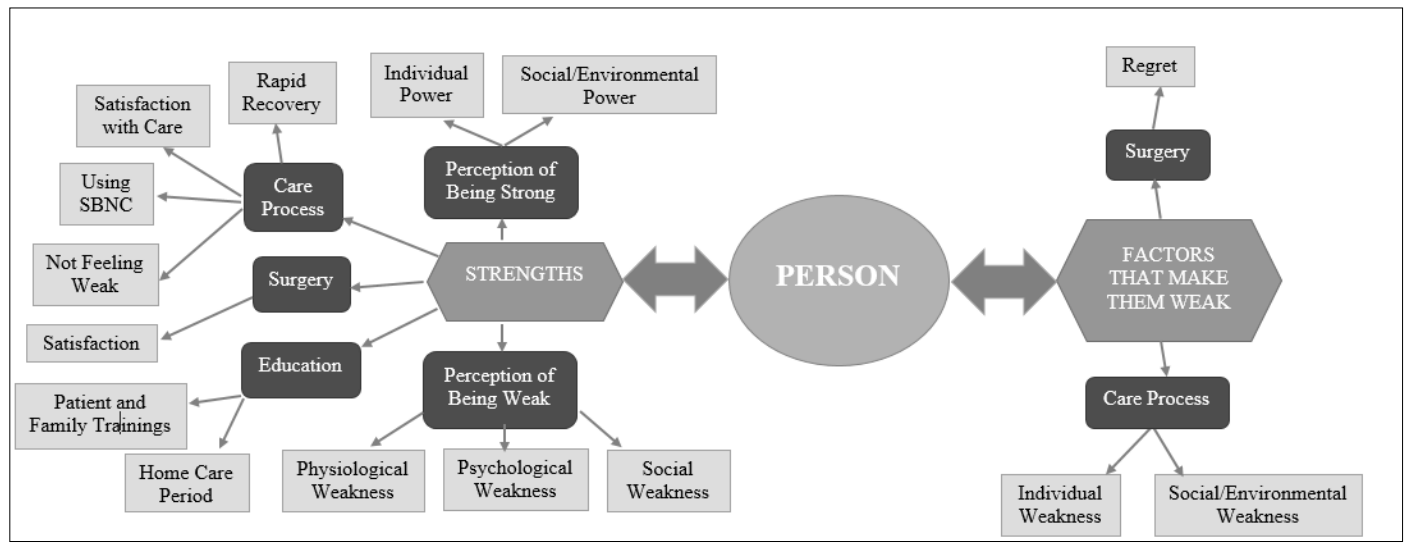

Figure 3. Categories, main themes and sub-themes of the postoperative period 
According to the analyses performed, three categories consisting of 'Strengths', 'Factors That Make Them Weak' and 'Surgery' were determined in the preoperative period and two categories consisting of 'Strengths' and 'Factors That Make Them Weak' were determined in the postoperative period. According to the analyses performed, seven main themes consisting of "Perception of Being Strong", "Perception of Being Weak", "Care Process", "Effects of Heart Disease", "Reason for the Occurrence of the Disease", "Need for Knowledge" and "Solution Seeking" were determined in the preoperative interviews, and five main themes consisting of "Perception of Being Strong", "Perception of Being Weak", "Surgery", "Care Process" and "Education" were determined in the postoperative interviews.

\section{A. Results of the preoperative period}

According to the interviews conducted in the preoperative period, 7 main themes consisting of 'Perception of Being Strong,' 'Perception of Being Weak', 'Care Process', 'Effects of Heart Disease,' 'Reason for the Occurrence of the Disease,' 'Need for Knowledge', and 'Solution Seeking' were determined in the categories of 'Strengths', 'Factors That Make Them Weak' and 'Surgery', and their sub-themes were created.

\section{A.1. Strengths}

This category consisted of the main themes of "Perception of Being Strong", "Perception of Being Weak" and "Care Process".

\section{Perception of being strong}

This consisted of two sub-themes including "Individual Power" and "Social/Environmental Power". Most of the patients and their relatives expressed being strong as "Being Rich $(\mathrm{n}=10)$ ", "Struggling $(\mathrm{n}=7)$ " and "Being Healthy $(\mathrm{n}=7)$ ".

\section{Perception of being weak}

It consisted of three sub-themes including "Physiological Weakness", "Psychological Weakness" and "SocialWeakness". Most of the patients and their relatives expressed "Being Weak $(\mathrm{n}=4)$ " as "Giving Up $(\mathrm{n}=6)$ ", "Failing $(\mathrm{n}=5)$ " and "Insufficiency of the Person and His/Her Family, Being Passive in Everything".

\section{Care process}

This consisted of one sub-theme "Recovery". The patents expressed "Positive Effect $(n=15)$ " by stating that "their strengths would positively affect the care process, which would give them experience and would strengthen them" and "Hope $(n=14)$ " by stating that "their strengths increased their hope for recovery, morale and recovery would affect each other, and they would feel the effect of care with their strengths over time".

\section{A.2. Factors that make them weak}

This category consisted of the main themes of "Reason for the Occurrence of the Disease", "Effects of Heart Disease" and "Need for Knowledge".
Reason for the occurrence of the disease

This consisted of three sub-themes including "Physiological Reasons", "Psychological Reasons" and "Genetic Reasons". They expressed "Family History $(n=4)$ ", "Stress $(n=3)$ " and "Decrease in Physical Movement $(n=2)$ " while describing the reasons for the occurrence of the disease.

\section{Effects of heart disease}

This consisted of four sub-themes including "Physiological State", "Psychological World", "Social Life" and "Activities of Daily Living". Most of the patients described the effects of heart disease as "Fatigue $(\mathrm{n}=16)$ ", "Chest Disorders $(\mathrm{n}=15)$ ), "Pain $(\mathrm{n}=14)$ " and "Restriction in Social Life $(\mathrm{n}=13)$ ".

“... when I went 50-100 meters, I was immediately squeezing my chest, there was burning on the chest, sweating started and came over me, I was sitting due to sweating for a 5-10 min. I was breathing and then I got up and walked again." (P.1)

\section{Need for knowledge}

This consisted of four sub-themes including "Disease", "Preoperative Period", "Intraoperative Period" and "Postoperative Period and Treatment". While patients' needs for knowledge concerning the surgical process were described, they expressed that "They did not know anything and nobody told them $(n=20)$ " about the preoperative and postoperative periods.

"...The tests will be finished and then they will perform surgery ... I have no other information." (P.20)

\section{A.3. Surgery}

This category consisted of the main theme of "Solution Seeking" since patients considered surgery as a solution.

\section{Solution seeking}

It consisted of five sub-themes including "Difficulties Experienced", "Comorbid Disease", "Failure of Coronary Angiography", "Physician's Decision" and "Risk of Heart Attack". The patients mostly described the decision-making process for surgery as "Physician's Decision $(\mathrm{n}=14)$ ), "Risk of Heart Attack $(\mathrm{n}=4)$ " and "Failure of Coronary - - Angiography $(\mathrm{n}=3)$ ".

"...Well, my doctor told, I said you know better. He said that surgery was needed and the sooner would I, the better would I be. I also said you know better than me" (P.11)

\section{B. Results of the postoperative period}

The themes of the participants in the postoperative period were determined under the groups of "Strengths and Factors that Make Them Weak", and their main and sub-themes were created. 5 main themes consisting of 'Perception of Being Strong, 'Perception of Being Weak', 'Surgery', 'Care Process' and 'Education' were determined in the groups of "Strengths" and "Factors that Make Them Weak" in the postoperative interviews. 


\section{B.1. Strengths}

This category consisted of the main themes of "Perception of Being Strong", "Perception of Being Weak", "Surgery", "Care Process and Education".

\section{Perception of Being Strong}

It consisted of two sub-themes including "Individual Power" and "Social/Environmental Power". In the postoperative period, most of the patients and their relatives mostly described their thoughts and behaviors about the perception of being strong and what being strong meant to them as "Being Healthy $(\mathrm{n}=11)$ ", "Self-Sufficiency $(\mathrm{n}=8)$ " and "Environmental Support $(\mathrm{n}=5)$ ".

"Being self-sufficient, being strong. How can I say? (Thinking...) I mean it is to get up from this bed by drawing strength from me without my wife, being able to walk alone, in other words, to use my strength to meet my needs ..... (P.2)

\section{Perception of being weak}

It consisted of three sub-themes including "Physiological Weakness", "Psychological Weakness" and "Social Weakness". Most of the patients expressed the perception of being weak as "Giving Up (n=5)" and "Being Weak (n=6)".

"Giving up in the face of difficulties... not struggling." (P.7)

"Self-release, to give up life." (P.13)

\section{Surgery}

The patients were asked to complete the sentences of I am glad I had surgery because...., "Satisfaction" that would be appropriate for them, and the statements of the patients were structured in accordance with the following two sub-themes under the third main theme "Surgery".

The patients mentioned 3 concepts including "Getting Healthy $(\mathrm{n}=12)$ ", "Risk of Heart Attack $(\mathrm{n}=8)$ " and "Fear of Death $(\mathrm{n}=6)$ " under the sub-theme of "Satisfaction" while describing their thoughts and feelings about having surgery.

"I am glad I had surgery because I would constantly feel uneasy for a heart attack ...but now, I've had surgery and I'm getting better slowly. I feel better, I believe that I will be better...”. (P.15)

\section{Care Process}

It consisted of four sub-themes including "Rapid Recovery", "Satisfaction with Care", "Using SBNC" and "Not Feeling Weak". While the patients were describing the effects of their strengths on the care process, they mostly talked about the sub-themes "Rapid Recovery (n=25)", "Satisfaction with Care $(n=25)$ " and "Using SBNC $(n=21)$ " expressing that "they recovered faster than expected", "they were pleased because of the increased courage" and "they would use the SBNC in all areas".

"It has affected positively. It made me recover faster, my selfconfidence has increased, I have started to feel stronger, how can tell, I am happy." (P.21)
"I am so glad. I never imagined it before I came here. I liked the fact that you asked my opinion in every respect. It impressed me that I recovered more quickly and was very pleased in this respect." (P.13)

\section{Education}

It consisted of two sub-themes including "Patient and Family Trainings" and "Home Care Period". While the patients were describing their thoughts and behaviors related to the effect of individual patient and family trainings on the care process, they mostly talked about the sub-themes "Patient and Family Trainings $(\mathrm{n}=12)$ " and "Home Care Period $(\mathrm{n}=7)$ " expressing that "it had a positive effect and was very beneficial" and "it was very good for them to have a written document".

"Our doctor told us a little, but we had some questions to ask, of course you told them. One forgets with the excitement of being discharged. Thank you very much for the information and books you provided." (P.19)

\section{B.2. Factors that make them weak}

This category consisted of the main themes of surgery and care process.

\section{Surgery}

The patients were asked to complete the sentences of I wish I had not had surgery because... .. "Regret" that would be appropriate for them, and the statements of the patients were structured in accordance with two sub-themes under the third main theme "Surgery".

While the patients were describing their thoughts and feelings about having surgery, under the sub-theme of regret, one of the patients expressed his regret by stating that he had never stayed in hospital previously and therefore he wish he had not had surgery.

"I wish I had not had surgery because I have never stayed in hospital, but I had a risk of death, therefore I had to stay."(P.12)

\section{Care process}

Care process, which was the second main theme, consisted of two sub-themes including "Individual Weakness" and "Social/ Environmental Weakness". While the patients were describing their thoughts and behaviors related to their strengths and the factors that make them weak in the care process and the methods of coping with them, they mostly expressed difficulty in "Physical Activity $(\mathrm{n}=7)$ " and "Intensive Care Unit $(\mathrm{n}=7)$ ".

"I felt weak in the intensive care unit, well, I was naked with a hose in my mouth, it was cold, it is too cold in there ... But I did not give up, I said to myself "you would achieve this" ... do this job, I immediately started the exercises, my feet warmed, it was good when my legs moved. Then I said that Mrs. Nurse was telling the truth (laughs..... (P.11) 


\section{DISCUSSION}

The discussion section consists of patients' feelings and thoughts, strengths and the factors that made them weak in the preoperative and postoperative processes. On the preoperative period in this study, patients indicated that they could get support from their families, relatives, environment and physicians in coping with this process and adapting to the process. In the study of Mooney, et al., 70\% of coronary artery surgery patients stated that they had difficulty in maintaining a regular social life [15]. Bergvik, et al., indicated that coronary artery surgery patients needed the support of their relatives to plan activities and perform these activities in their daily lives [16]. It was determined that coronary artery surgery patients had significant deteriorations in daily life, social relations and psychology $[3,15,16]$. Coping strategies under strengths are important in adapting to the chronic state $[3,15]$. This process is consistent with Knowledge and Wisdom, Courage and Superiority capacity, the ability to predict the future with the impressions of the individual about past experiences, one of basic principles on which the SBNC is based. These results describe patients' "Individual Centered Care, Empowering the Individual, Holistic, Individual and Personalized Care, Health Promotion and Disease Prevention and Collaborative Care" capacity, one of basic principles on which the SBNC is based.

On the preoperative period in this study, within the framework of "Knowledge and Wisdom, Courage, Superiority and Moderation" of the SBNC which constituted the basis of the study, the reasons for patients to decide on surgery were expressed as the risk of heart attack, failure of coronary angiography, difficulties experienced, comorbid diseases and physician's decision. The decision for surgery is considered as an experience that threatens the patient both physiologically and psychologically. However, the patients who will undergo surgery feel scared and anxious since they do not have information about the surgical process [15-17]. In the literature and in this study, it appears that the patients who are scheduled for surgery do not have enough information about the surgical process and they need to get more knowledge [5,15-18]. Nevertheless, it is reported that the training given to patients in this process is limited and usually provided by the physician $[15,19]$. However, the nurse has important responsibilities in ensuring coordination within the team and in the planning and implementation of training on the surgical process and discharge $[17,19]$. In this study, when patients who underwent CABG were asked where they were informed about CAD and the surgical process, most of the patients indicated that they did not receive any information. After the individual and family trainings provided by the researcher in accordance with the SBNC, most of the patients indicated that those trainings were very useful and they would use SBNC in preoperative surgical patients.

On the postoperative period in this study, most of the patients indicated that they effectively coped with disease and surgery. These statements explain the principle of "Courage, Moderation and Superiority" expressing the individual's belief in the ability to achieve a behavior, one of the basic principles on which the SBNC is based. Leegaard and et al. (2008) indicated that the internal factors affecting the compliance of patients with CAD and treatment were personality, and the external factors were social activity, family, friend relations and support of health care professionals [4]. Physiological, behavioral, environmental and socioeconomic factors play a role in the effective management of chronic diseases [3]. Mohammadi, et al., indicated that the patients found ways to cope with the process by changing their environment, motivating themselves and reducing their demands and that the psychological effects of the disease could be coped with by self-control, family, friends and spouse's support [20]. Emotional health is important in coping with CAD. According to the "Knowledge and Wisdom, Courage and Superiority" capacity, one of the basic principles on which the SBNC is based, patients set targets in the postoperative period by coding their past experiences with thoughts and symbols and making future plans. Some patients indicated that "they were further encouraged after surgery", "they were able to realize some thoughts that they could not do before the surgery", "they could express themselves better", "this situation made them happy" and "they felt like a newborn". It is stated that posttraumatic growth is more frequently observed in those with life-threatening diseases such as cancer and CAD, and in these studies, individuals achieve growth in many areas such as selfperception, life philosophy, and mental development in the post-operative period [21]. The individual learns to make and implement plans for the future based on his past experiences, accepts the process and adapts to the post-operative process with Content Centered Care, Collaborative Care and Empowerment Movements and Health Promotion and Disease Prevention, and Determination, Positive Thinking and Perseverance.

On the postoperative period another result obtained from this study was that getting individual centered care increased patient satisfaction and improved the feeling of confidence between health worker and patient. Patient satisfaction expressed at the end of the surgical period in line with individual-centered care is a complex concept affected by various factors and is one of the most important indicators of the quality patient management [12]. In some studies, it was also found that interpersonal communication and behavior of staff regarding the treatment process and information about the disease increased patient satisfaction $[5,17,19]$. SBNC offers nurses the opportunity to provide individual and holistic care to patients, in this respect, the use of the philosophy in this patient group is important. SBNC increases patients' compliance with the surgical process by revealing their strengths and empowers them and also reveals their weaknesses and gives them the opportunity to turn them into strengths, and facilitates their compliance to the surgical process.

\section{Strengths and Limitations}

Human factor constitutes the strengths of qualitative studies. Patients' experiences are closely associated with their culture and past experiences. As the first author of the present study has clinical experience in the field of cardiovascular nursing, the analysis of the data was carried out continuously discussing and reflecting on identified main themes and sub-themes to 
decrease the risk of research bias. The translated quotations and the pattern of the data and interviews were further discussed until consensus was reached within the whole research team, which confirms the dependability of the data. Multiple researchers analyzing the data independently then conjointly established credibility and trustworthiness of the data. The use of various data collection methods (interviews and written reflections) preserved credibility, providing multiple constructions of the data, and enhanced the richness of the interpretation. Furthermore, the transferability is enhanced by the detailed description of the design of the study, the analysis of the data and the rich description of the context and findings. Nevertheless, the fact that the study provided an opportunity to examine in depth the experiences of CABGS patients and was the first study using SBNC made the results of the study unique and valuable and constituted the strength of the study. However, we acknowledge that it is a single centre study, which might limit transferability. The fact that the results obtained as a result of the study were based on the patients' own statements constituted the factors that made the study weak, therefore, the results of the study cannot be generalized.

\section{Conclusion}

According to SBNC, the strengths that were mostly expressed by the patients provided with care were the "desire to manage the surgical process", "ability to provide basic physiological and safety needs", "hope for life", "strong desire to learn" and "having family support". It was concluded that the factors that made individuals most weak in the surgical process were the "lack of knowledge about disease and treatment process", "limitation of physical and social activity" and "being in the intensive care unit". The patients emphasized that they were satisfied with the care provided in accordance with this philosophy in the surgical process. This new philosophy in patient management is effective because it increases patients' hopes for life, healing and facilitating adaptation to the surgical procedure. In the future, education and training about CABGS must focus on patient needs regarding the surgical process and encourage them to take part in their care. In line with these results, it is recommended to use SBNC for different diseases and processes and to discuss the results.

\section{Compliance with Ethical Standards}

Ethical approval: Approval for the study was obtained from the Scientific Ethics Committee of a University (Ethics Committee Approval No. 2015-86). Written permission was taken from the Administration of University Hospital where the study was to be conducted. Informed consent was obtained from all individual participant included in the study.

Financial Support: The authors have no relevant financial information to disclose.

Conflict of Interest: The authors have no potential conflicts to disclose.

Author Contributions: YA, MYvG : Study concept/Design, YA: Data collection, YA : Data analysis and interpretation,
YA: Drafting manuscript, YA, MYvG: Critical revision of manuscript, YA, MYvG: Final approval and accountability, YA, MYvG: Technical or material support, YA, MYvG: Supervision.

\section{REFERENCES}

[1] World Health Organization: Cardiovascular diseases (CVDs). World Health Organization; 2017. Available at: https:// www.who.int/news-room/fact-sheets/detail/cardiovasculardiseases-(cvds). (Accessed June 2020).

[2] Roosens C, Heerman J, De Somer F, Caes F, Van Belleghem Y, Poelaert J I. Effects of offpump coronary surgery on the mechanics of the respiratory system, lung, and chest wall: comparison with extracorporeal circulation. CritCare Med 2002;30:2430-7. doi: 10.1097/00003.246.200211000-00005

[3] Tolmie EP, Lindsay GM, Belcher PR. Coronary artery bypass graft operation: patients' experience of health and well-being over time. Eur J CardiovascNurs 2006;5:228-36. doi: 10.1016/j. ejcnurse.2006.01.007

[4] Leegaard M, Fagermoen M S. Patients' key experiences after coronary artery bypass grafting: a synthesis of qualitative studies. Scand J Caring Sci 2008;22:616-28. doi: 10.1111/j.14716712.2007.00556.x.

[5] Whitsitt DR. Coping strategies and adaptation to coronary artery bypass surgery as experienced by three couples. Heart Lung 2012;41:350-9. doi: 10.1016/j.hrtlng.2012.02.013

[6] Diaz M, Larsen B. Preparing for successful surgery: an implementation study. Perm J 2005;9:23-7.

[7] Gottlieb LN. Strengths-based nursing care. Canada: Springer Publishing Company, 2013.

[8] Gottlieb LN. Strengths-based nursing. Am J Nurs 2014;114:2432. doi: 10.1097/01.NAJ.000.045.3039.70629.e2.

[9] AltınbaşY, van Giersbergen M Y. Strenghts-based nursing care. Health Sciences Journal of Adiyaman University 2019;5:165263. doi: 10.30569/adiyamansaglik.528795

[10] SandelowskiM.Focuson researchmethods-whateverhappened to qualitative description? Res Nurs Health 2000;23:33440. doi:10.1002/1098-240X(200008)23:4<334::AIDNUR9>3.0.CO;2-G

[11] Kim H, Sefcik J S, Bradway C. Characteristics of qualitative descriptive studies: a systematic review. Res Nurs Health 2017;40:23-42. doi: 10.1002/nur.21768

[12] Morys JM, Bellwon J, Höfer S, Rynkiewicz A, Gruchała M. Quality of life in patients with coronary heart disease after myocardial infarction and with ischemic heart failure. Arch Med Sci 2016;12:326-33. doi: 10.5114/aoms.2014.47881

[13] Emslie C. Women, men and coronary heart disease: a review of the qualitative literature. J Adv Nurs 2005;51: 382-95. doi: 10.1111/j.1365-2648.2005.03509.x.

[14] Smith J, Osborn M. Interpretative phenomenological analysis. In: Smith JA, ed. Qualitative Psychology: A Practical Guide to Research Methods. 3rd edition. London, England: Sage, 2015:54-80.

[15] Mooney M, Fitzsimons D, Richardson G. "No more couch potato!" Patients' experiences of a pre-operative programme 
of cardiac rehabilitation for those awaiting coronary artery bypass surgery. Eur J Cardiovasc Nurs 2007;6:77-83. doi: 10.1016/j.ejcnurse.2006.05.002

[16] Bergvik S, Sorlie T, Wynn R. Approach and avoidance coping and regulatory focus in patients having coronary artery bypass graft surgery. J Health Psychol 2010;15:915-24. doi: $10.1177 / 135.910 .5309359542$

[17] Anderson L, Brown J P R, Clark A M, et al., Patient education in the management of coronary heart disease. Cochrane Database Syst Rev 2017;6:CD008895. doi: 10.1002/14651858. CD008895.pub3

[18] Lie I, Bunch E H, Smeby N A, Arnesen H, Hamilton G. Patients' experiences with symptoms and needs in the early rehabilitation phase after coronary artery bypass grafting.
Eur J Cardiovasc Nurs 2012;11: 14-24. doi: 10.1016/j. ejcnurse.2010.09.004

[19] Dunckley M, Ellard D, Quinn T, Barlow J. Recovery after coronary artery bypass grafting: patients' and health professionals' views of the hospital experience. Eur J Cardiovasc Nurs 2007; 6: 200-07. doi: 10.1016/J.EJCNURSE.2006.09.003

[20] Mohammadi N, Abbasi M, Nasrabadi A N, Salehiomran A, Davaran S, Norouzadeh R. Passion for life: lived experiences of patients after coronary artery bypass graft. J Tehran Heart Cent 2015;10:129-33.

[21] Leung Y W, Alter DA, Prior PL, Stewart D E, Irvine J, Grace S L. Posttraumatic growth in coronary artery disease outpatients: relationship to degree of trauma and health service use. J Psychosom Res 2012;72:293-9. doi: 10.1016/j. jpsychores.2011.12.011 